\title{
OVERVIEW OF ADVERSE EVENTS ASSOCIATED WITH ANTI-CD19 CHIMERIC ANTIGEN RECEPTOR T-CELL THERAPY
}

\author{
Authors: \\ Ekaterina Vorozheikina, Magdalena Ruiz, Leticia Solari, Dmitry Ostasevich, Luis Mendoza
}

IQVIA

Medical and Scientific Services

Haematology and Oncology Division

Corresponding author:

Ekaterina Vorozheikina, MD, PhD

Ekaterina.Vorozheikina@quintiles.com

\begin{abstract}
Anti-CD19 chimeric antigen receptor (CAR) T-cells represent a novel immunotherapy that has shown remarkable success in the treatment of adult relapsed or refractory $(R / R) B$-cell nonHodgkin's lymphoma, adult $R / R$ mantle cell lymphoma, and $R / R$ acute paediatric lymphoblastic leukaemia. One barrier to the widespread use of CAR T-cell therapy is toxicity, primarily cytokine release syndrome (CRS) with a variable grade of severity. The main manifestations of CRS are fever, hypotension, cytopenia, organ dysfunction among others. Neurological toxicities vary widely and range from headaches to encephalopathy. In addition, anti-CD19 CAR T-cell therapy provokes an array of less frequent events, such as coagulopathies, delayed cytopenia, and cardiovascular toxicities. In general, toxicities are usually reversible and resolve on their own in most cases, though severe cases may require intensive care and immunosuppressive therapy. Deaths due to CRS, neurologic toxicity and infectious complications have been reported, which highlights the gravity of these syndromes and the critical nature of appropriate intervention. In this paper, we look at all available FDA- and EMAapproved information about the pathophysiology, clinical manifestations, risk factor reviews of existing toxicity grading systems, current management strategies, and guidelines for anti-CD19 CAR T-cell toxicities. We also present new approaches, which are under investigation, to mitigate these adverse events.
\end{abstract}

KEYWORDS: CAR T-cells, chimeric antigen receptor $\mathbf{T}$ cells, cytokine release syndrome; central nervous system toxicity, neurotoxicity; adverse events, pathophysiology

Declaration of Competing Interest

The authors declare that they have no known competing financial interests or personal relationships that could have appeared to influence the work reported in this paper.

Funding Statement

No external funding was received for this manuscript

\section{INTRODUCTION}

T lymphocytes play an essential role in cell-mediated adaptive immunity by recognition of peptides bound to the T-cell receptor (TCR). Researchers first identified molecular evidence of T-cell receptors (TCRs) in the 1980s [1,2]. The TCR molecules have the specificity to optimally match and subsequently recognize tumoral antigens, which is the foundation of T-cell-mediated therapies. The chimeric antigen receptor (CAR) is a fusion protein comprised of an antigen recognition moiety and T-cell signalling domains [3-5], which, in a single engineered molecule, can reprogram the specificity, function, and metabolism of T lymphocytes [6,7]. 
Chimeric antigen receptor-modified $\mathrm{T}(\mathrm{CAR} \mathrm{T})$ cells, which are genetically engineered to express CAR molecules that target surface antigens on tumours and other cells, can overcome some of the limitations of T cells. Since the first demonstration of cytotoxicity to target-bearing cells, CAR T- cells have been extensively investigated in preclinical and clinical studies and have exhibited dramatic efficacy in treating haematological malignancies [8-12].

The U.S. Food and Drug Administration (FDA) and the European Medicine Agency (EMA) have approved some anti-CD19 CAR T-cell products: tisagenlecleucel (Kymriah®, Novartis) for patients up to 25 years of age with multiple relapsed or refractory (R/R) B-cell precursor acute lymphoblastic leukaemia [13], tisagenlecleucel and axicabtagene ciloleucel (Yescarta®, Kite), which are FDA- and EMA-approved for the treatment of adult patients with R/R large B-cell lymphoma after two or more lines of systemic therapy, including diffuse large B-cell lymphoma (DLBCL) not otherwise specified, primary mediastinal large B-cell lymphoma, high-grade B-cell lymphoma, and DLBCL arising from follicular lymphoma [14,15]. Recently, the FDA has approved two additional anti-CD19 CAR T-cell products. Brexucabtagene autoleucel (Tecartus ${ }^{\circledR}$, Kite) was approved for the treatment of adult patients with R/R mantle cell lymphoma (MCL) [16] and lisocabtagene maraleucel (Breyanzi ${ }^{\circledR}$, Bristol-Myers Squipp) approved for the treatment of adult patients with R/R large B-cell lymphoma after two or more lines of systemic therapy, including DLBCL not otherwise specified (including DLBCL arising from indolent lymphoma), high-grade B-cell lymphoma, primary mediastinal large B-cell lymphoma, and follicular lymphoma grade 3B [17]. Figure 1 illustrates the basic characteristics technical facts of the currently approved CD19 CAR T-cell therapies.

Figure 1. Approved CAR T-cell therapies
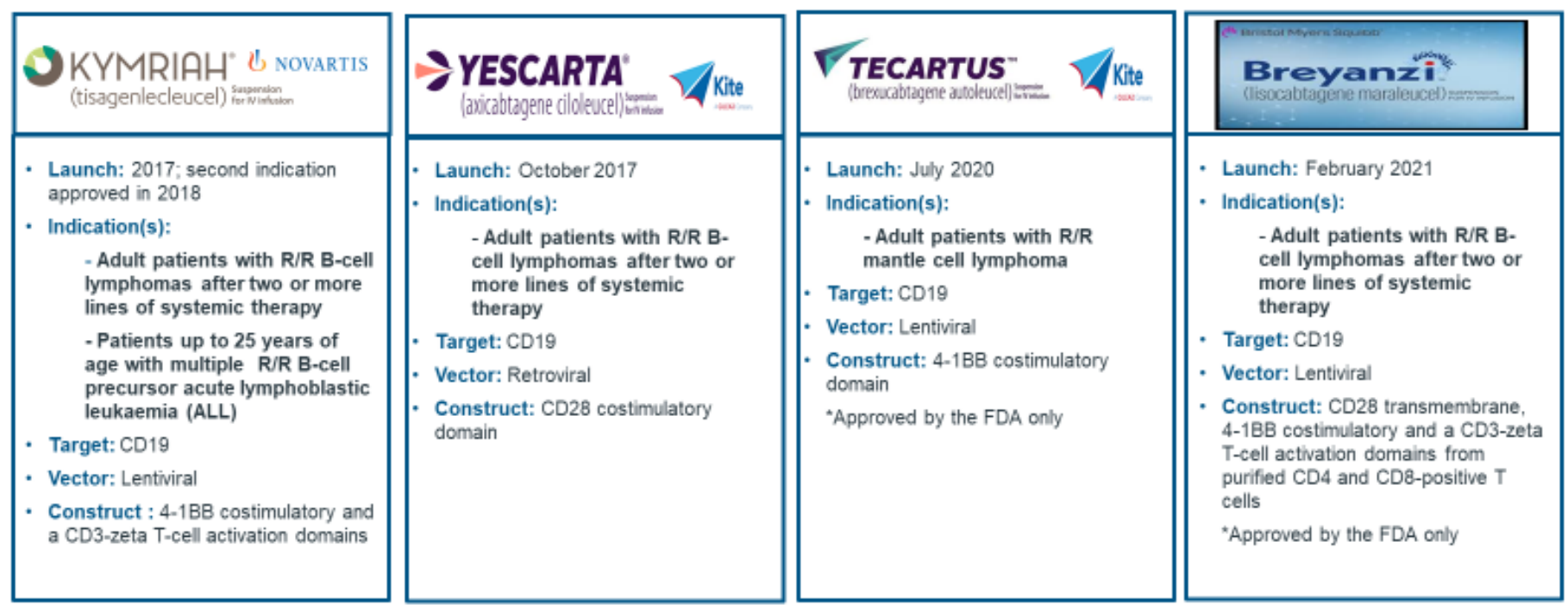

While CAR T-cell clinical trials have shown positive results, severe toxicities are possible and can be lifethreatening. The most common severe toxicity is a systemic inflammatory response termed cytokine release syndrome (CRS). CRS is thought to be caused by the release of inflammatory cytokines from CAR $\mathrm{T}$ and other immune cells. CAR T-cells can also cause neurologic toxicity, a heterogeneous and poorly understood disorder with variable clinical presentation and severity. Toxicities are usually reversible and resolve on their own in most cases, though severe cases may require intensive care and immunosuppressive therapy. Deaths due to CRS and neurologic toxicity have been reported, which highlights the gravity of these syndromes and the critical nature of appropriate interventions. Therefore, approved anti-CD19 CAR T-cell products are available only through a restricted program under a Risk Evaluation, and Mitigation Strategy (REMS), which requires that certified healthcare facilities must have on-site, immediate access to tocilizumab (anti-IL-6) and other immunosuppressive medications if needed for the treatment of CRS. Certified healthcare facilities must also ensure that healthcare providers who prescribe, dispense, or administer CAR T-cells are trained in the management of the associated toxicities. 
In this paper, we describe the diversity of toxicities that have been reported following infusion of approved anti-CD19 CAR T-cell therapies, including their pathophysiology, clinical manifestations, review of existing toxicity grading systems, and management approaches. We also present new strategies that are under investigation to overcome CAR T-cell toxicities.

\section{CYTOKINE RELEASE SYNDROME}

CRS is the most commonly observed toxicity in CAR T-cell therapies and it induces a systemic inflammatory response derived from the anti-tumoral activity of T lymphocytes [18]. It can range in severity from low-grade constitutional symptoms to a high-grade syndrome associated with life-threatening multiorgan dysfunction [19].

\section{Pathophysiology}

Current understanding of the molecular mechanisms of CRS is limited. CRS occurs due to on-target effects induced by CAR T-cells binding to antigens and subsequent activation of T lymphocytes, bystander immune cells (monocytes, macrophages, and dendritic cells), and non-immune cells, such as endothelial cells. The final consequence is an excessive immune response with a massive release of a range of cytokines and chemokines.

The intensity of the inflammatory response translated into CSR severity may differ depending on the host's characteristics, such as the type of tumour, tumour burden, and the therapeutic agent. Interleukin-6 (IL-6), interleukin-10 (IL-10), and interferon (IFN)- $\gamma$ are among the core cytokines that are consistently found to be elevated in the serum of patients with CRS.

The levels of IFN- $\gamma$ remain high during CRS occurrence. IFN- $\gamma$ causes fever, chills, headache, dizziness, and fatigue. Secreted IFN- $\gamma$ induces the activation of other immune cells, most importantly, macrophages [209]. The activated macrophages produce excessive levels of additional cytokines, such as tumour necrosis factor alpha (TNF- $\alpha$ ), which is responsible for flu-like symptoms similar to those induced by IFN- $\gamma$. TNF- $\alpha$ is also responsible for watery diarrhoea, vascular leakage, cardiomyopathy, lung injury, and the synthesis of acutephase proteins.

IL-6 is a proinflammatory cytokine that has a crucial role in CRS pathophysiology [21]. IL-6 mainly signals through both classic-signalling and trans-signalling pathways, and the distinction depends on the expression patterns of the IL-6 receptor (IL-6R) and glycoprotein (gp) 130 on the cell surface. The final consequence of activating both routes is the involvement of the JAK/STAT signalling pathway. The expression of membranebound IL-6R is restricted to hematopoietic cells (i.e., macrophages, neutrophils, T lymphocytes) and hepatocytes, whereas membrane-bound gp130 is expressed abundantly on all cell types [22].

Thus, classical or cis signalling, which is activated at low levels of IL-6, affects only a few cell types and mediates effects on the acquired immune system (B and $\mathrm{T}$ lymphocytes) and innate response. By contrast, trans-signalling is the main pathway of activation at higher levels of IL-6 (as occur in patients with CRS), and it affects most cell types producing a deregulated proinflammatory response.

IL-6 contributes to other severe medical problems, such as vascular leakage and activation of the complement and coagulation cascade, which induces disseminated intravascular coagulation (DIC) via trans-signalling [23]. Serum IL-6 levels positively correlate with the serum levels of plasminogen activator inhibitor-1 (PAI1) [24]. Elevated PAI-1 levels exacerbate the progression of systemic inflammation, primarily disseminated intravascular coagulation, and may act as a predictor of CRS disease progression. In a cohort of 35 paediatric and adult B-ALL patients receiving CD19 CAR T-cell therapy, the risk of severe CRS was correlated with peak levels of IL-6, soluble IL-6R, IFN- $\gamma$, and soluble gp130 [25]. 
The endothelium plays a vital role in the pathophysiology of CRS by amplifying the inflammatory response. The clinical severity of CRS is associated with activation of endothelial cells, causing endothelial injury and coagulopathy through the induction of vascular leakage and tissue hypoxia, resulting in hypotension and multiple organ dysfunction. Typical markers of endothelial activation such as angiotensin II and von Willebrand factor are often elevated in the serum of patients with CRS [26].

\section{Clinical presentation}

CRS is a harmful systemic hyperactivated immune state that can lead to vascular damage, transaminitis, coagulopathy, multiple organ dysfunction, and death. Clinical manifestations of CRS can range from mild, flu-like symptoms to severe life-threatening conditions. Fever is usually the first symptom of CRS. The onset of fever can be quite variable, ranging from a few hours to more than a week after CAR T-cell infusion. Temperatures can exceed $40^{\circ} \mathrm{C}$ and may be accompanied by rigours, malaise, headaches, myalgias, arthralgias, and anorexia, which can rapidly progress to life-threatening capillary leakage tachycardia, hypotension, and hypoxia with multiorgan system failure. The duration is variable, with resolution within a few days to two to three weeks after CAR T-cell infusion. The differences in the grading of toxicities across trials and institutions highlight the need to develop a consensus grading system for CAR T-cell-related toxicities. The American Society for Blood and Marrow Transplantation (ASBMT) published the ASBMT Consensus Grading System for CRS and neurological toxicity [27]. The ASBMT consensus grading system for CRS is based on the assessment of three vital signs: temperature, blood pressure, and oxygen saturation, together with the type of intervention required for patient management. Table 1 shows the time of onset, duration, and severity of CSR in different studies of patients with refractory/relapsed B-cell lymphoma and B-cell lymphoblastic leukaemia, respectively. The time of onset reported in these studies ranged from 1 to 22 days. The duration of the event was in the range of 2-30 days. The range of incidence for all grades of CSR severity was between $35 \%$ to $93 \%$ and between $4 \%$ to $46 \%$ in grade 4 and 3, respectively.

Table 1. CRS After Autologous Anti-CD19 CAR T-cell Therapy Reported in Registrational Studies for FDA And EMA Approvals

\begin{tabular}{|c|c|c|c|c|c|}
\hline $\begin{array}{l}\text { Approved CAR T- } \\
\text { cell therapies }\end{array}$ & Tisagenlecleucel [28] & $\begin{array}{l}\text { Axicabtagene } \\
\text { Ciloleucel [29] }\end{array}$ & $\begin{array}{l}\text { Brexucabtagene } \\
\text { autoleucel [53] }\end{array}$ & Tisagenlecleucel [32] & $\begin{array}{l}\text { Lisocabtagene } \\
\text { maraleucel [78] }\end{array}$ \\
\hline $\begin{array}{l}\text { Patients enrolled } \\
\text { (treated) }\end{array}$ & $160(106)$ & $111(101)$ & $74(68)$ & $107(75)$ & $299(268)$ \\
\hline Population & $\begin{array}{l}\text { Adults R/ R B-cell } \\
\text { lymphomas }\end{array}$ & $\begin{array}{l}\text { Adults R/R B- cell } \\
\text { lymphomas }\end{array}$ & $\begin{array}{l}\text { Adults } \mathrm{R} / \mathrm{R} \text { mantle cell } \\
\text { lymphoma }\end{array}$ & $\begin{array}{l}\text { Pediatric \& young } \\
\text { adults R/R B-Cell } \\
\text { Lymphoblastic } \\
\text { Leukemia }\end{array}$ & $\begin{array}{l}\text { Adults R/R B-cell } \\
\text { lymphomas }\end{array}$ \\
\hline $\begin{array}{l}\text { Median follow up } \\
\text { (months) }\end{array}$ & 19.3 & 27.1 & 12.3 & 13.1 & 18.8 \\
\hline $\begin{array}{l}\text { CAR T-cell dose, } \\
\text { Median }\end{array}$ & $3.1 \times 10^{8}$ cells & $2.0 \times 10^{6} \mathrm{celll} / \mathrm{kg}$ & $2 \times 10^{6}$ cells $/ \mathrm{kg}$ & $3.1 \times 10^{6}$ cell $/ \mathrm{sg}$ & $50-100 \times 10^{6}$ cells \\
\hline CRS all grades & $58 \%$ & $93 \%$ & $91 \%$ & $77 \%$ & $46 \%$ \\
\hline Grade 3 or 4 & $23 \%$ & $13 \%$ & $15 \%$ & $46 \%$ & $4 \%$ \\
\hline $\begin{array}{l}\text { Time to onset, } \\
\text { median (range) }\end{array}$ & 3 days (1-9) & 2 days (1-12) & 2 daxs (1-13) & 3 days (1-22) & 5 daxs (1 to 15$)$ \\
\hline $\begin{array}{l}\text { Duration median } \\
\text { (range) }\end{array}$ & 7 days $(2-30)$ & 8 days (NR) & 4 daxs (1-9) & 8 days (1-6) & 5 days $(1-30)$ \\
\hline Tocilizumab use & $14 \%$ & $43 \%$ & $59 \%$ & $37 \%$ & $20 \%$ \\
\hline Vasopressors use & $6 \%$ & $17 \%$ & $16 \%$ & $25 \%$ & $3 \%$ \\
\hline Steroid treatment & $10 \% *$ & $27 \%$ & $22 \%$ & NR & $10 \%$ \\
\hline
\end{tabular}




\section{Treatment}

Accurate monitoring for signs and symptoms of CRS along with prompt therapeutic management can mitigate adverse outcomes. A multidisciplinary approach with representatives from multiple medical disciplines, including haematology, neurology, critical care, immunology, and pharmacology, is vital to optimizing patient outcomes. General supportive care remains the pillar of treatment because a single therapeutic target for immunomodulation is ineffective. Patient hospitalization with close monitoring is recommended for at least seven days after CAR T-cell infusion. Monitoring should include assessments of vital signs, daily review of organ systems, physical exams including neurological assessment, complete blood count and metabolic profile, coagulation, and measurement of serum CRP and ferritin levels [35]. Cardiac monitoring by telemetry is advised starting from CAR T-cell infusion until resolution of any emergent CRS symptoms. Daily fluid balance and body weight should be strictly monitored, and intravenous maintenance of hydration is recommended for all patients with, or at the risk of developing, CRS. Patients who develop fever should be assessed for infection as undiagnosed infections can have catastrophic consequences in patients with CRS. Approximately $45 \%-50 \%$ of patients enrolled in the early CAR T-cell trials required intensive care management $[10,36]$. With more experience and earlier interventions in CRS management, this rate has decreased. In any case, since even severe CRS has a relatively good prognosis when appropriately treated, patients with CRS should be offered the full spectrum of modern critical care, including mechanical ventilation, if necessary. In addition to the clinical measures for early CSR detection and support, the use of IL-6 antagonists and corticosteroids should be considered.

\section{Tocilizumab}

Tocilizumab is a humanized, immunoglobulin G1k (IgG1k) antihuman IL-6R approved to treat rheumatoid arthritis. Tocilizumab prevents IL-6 binding to both cell-associated and soluble IL-6R and therefore inhibits classical and trans-IL-6 signalling. It was approved as a CRS treatment by the FDA in August 2017 and the EMA in June 2018. Tocilizumab induces a rapid reversal of CRS and has become the standard of care for CRS [37]. In general, tocilizumab is very well-tolerated with minimal adverse events (AEs). For severe CRS (grades 3 and 4) caused by CAR T-cell therapy, initial treatment with tocilizumab plus a corticosteroid is preferred rather than either agent alone, to achieve a more rapid and complete control of CRS. One study reported that early treatment with tocilizumab reduced fever and other CRS symptoms within one to three days but did not dampen the expansion of CAR T- cells in peripheral blood [38].

In contrast, high-dose steroids rapidly reversed CRS symptoms but ablated CAR T- cells and were associated with a recurrence of the disease after an initial response to CAR T-cell therapy [38]. At present, it is unclear if the early use of tocilizumab may contribute to an increased risk of neurologic complications due to transient increases in IL-6 (as IL-6R is blocked) [27]. Based on this hypothesis, initial treatment with steroids is preferred for patients with neurological findings consistent with immune effector cell-associated neurotoxicity syndrome (ICANS) without active CRS.

\section{Corticosteroids}

Corticosteroids are an effective treatment of CRS and a rapid steroid taper can generally be accomplished within several days without recurrence of CRS. Currently, corticosteroids are considered a second-line therapy for CRS and the main reason is that the response to tocilizumab may be faster than the response to corticosteroids. Also, corticosteroids appear to have more widespread effects on the immune system, and emerging evidence suggests that they mediate a more significant adverse effect on the antitumor activity of adoptively transferred T cells [38].

\section{Additional anti-CRS treatment}

Siltuximab is a murine, chimeric MoAb IL-6 antagonist. It is currently not approved for CRS treatment, but several centres have reported their experience with CAR T-cell-related CRS. Currently, it is considered for 
cases of tocilizumab-refractory CRS. One potential benefit of siltuximab is that it does not increase IL-6 levels after administration due to direct binding to IL-6 [39].

One of the challenges in the future management of CRS will be identifying additional targets for specific therapeutic interventions. Some of the proinflammatory cytokines as TNF $\alpha$ and IL-1 may be blocked by immunosuppressive agents (infliximab and etanercept for TNF $\alpha$ and anakinra for IL-1). Emapalumab is an anti-IFN- $\gamma$ that may contribute to the protection of the endothelium in treating CAR T-123, as demonstrated in preclinical models [40]. The contribution of those agents to the treatment of CRS is under development.

\section{CENTRAL NERVOUS SYSTEM TOXICITY}

CNS toxicity is the second most common adverse event observed with CAR T-cell therapy. The incidence of neurotoxicity across different trials is presented in Table 2. It can occur concurrently with CRS or, more commonly, after the successful treatment and resolution of CRS, although mild neurological symptoms may rarely occur in patients who never experienced CRS [35, 42]. It appears that the degree of neurotoxicity directly correlates with the degree of CSR and is associated with systemic vascular dysfunction [43].

Table 2. CNS Toxicity After Autologous Anti-CD19 CAR T-Cell Therapy Reported in Registrational Studies for FDA and EMA Approvals

\begin{tabular}{|l|l|l|l|l|l|}
\hline $\begin{array}{l}\text { Approved CAR T- } \\
\text { cell therapies }\end{array}$ & $\begin{array}{l}\text { Axicabtagene } \\
\text { ciloleucel (Yescarta) } \\
\text { [10] }\end{array}$ & $\begin{array}{l}\text { Tisagenlecleucel } \\
\text { (Kymriah) [52] }\end{array}$ & $\begin{array}{l}\text { Brexucabtagene } \\
\text { autoleucel (Tecartus) } \\
\text { [53] }\end{array}$ & $\begin{array}{l}\text { Tisagenlecleucel } \\
\text { (Kymriah) [32] }\end{array}$ & $\begin{array}{l}\text { Lisocabtagene } \\
\text { maraleucel } \\
\text { (Brexanzi) [78] }\end{array}$ \\
\hline $\begin{array}{l}\text { Patients enrolled } \\
\text { (treated) }\end{array}$ & $111(101)$ & $165(111)$ & $74(68)$ & 107 (75) & $299(268)$ \\
\hline $\begin{array}{l}\text { Population } \\
\text { Adults R/R B-cell } \\
\text { lymphomas }\end{array}$ & $\begin{array}{l}\text { Adults R/R B } \\
\text { lymphoma }\end{array}$ & $\begin{array}{l}\text { Adults R/R mantle cell } \\
\text { lymphoma }\end{array}$ & $\begin{array}{l}\text { Pediatric \& young } \\
\text { adults R/R B-Cell } \\
\text { Lymphoblastic } \\
\text { Leukemia }\end{array}$ & $\begin{array}{l}\text { Adults R/R B cell } \\
\text { lymphomas }\end{array}$ \\
\hline $\begin{array}{l}\text { Median follow up } \\
\text { (months) }\end{array}$ & 15.4 & 14 & 2.3 & 13.1 & 18.8 \\
\hline $\begin{array}{l}\text { Time to onset, } \\
\text { median (range) }\end{array}$ & 5 daxs (1 to 17) & 6 daxs (1 to 17) & 7 daxs (1 to 32) & within 8 weeks & 8 daxs (1 - 46) \\
\hline Duration median & 17 days & 14 daxs & 12 daxs & NR & 12 daxs \\
\hline $\begin{array}{l}\text { Neurological exents } \\
\text { all grades }\end{array}$ & $64 \%$ & $21 \%$ & $63 \%$ & $40 \%$ & $35 \%$ \\
\hline Grade 3 or 4 & $28 \%$ & $12 \%$ & $31 \%$ & $13 \%$ & $12 \%$ \\
\hline
\end{tabular}

$\mathrm{CNS}=$ central nervous system $; \mathrm{NR}=$ not reported $\mathrm{R} / \mathrm{R}=$ refractory $/$ relapsed

\section{Pathophysiology}

In mouse models, the underlying pathophysiology of CNS toxicity events is not fully understood. Two main potential explanations are postulated: passive diffusion of cytokines into the brain and migration of $\mathrm{T}$ cells into the CNS. Like CRS, cytokines, chemokines, and the degree of CAR T-cell expansion have been associated with the severity of neurotoxicity $[10,44]$. In the mice model, tocilizumab failed to protect against delayed lethal neurotoxicity, characterized by meningeal inflammation. Instead, anakinra abolished both CRS as well as neurotoxicity, resulting in extended leukaemia-free survival [45].

In addition to the well-described association between CAR T-cell expansion and toxicity, some published preclinical databases of xenogeneic mouse models suggest that monocytes/macrophages also play a crucial role in the development of CRS and CNS toxicity [45]. CAR T- cells were detected in the cerebrospinal fluid (CSF) of patients with neurotoxicity [41]. However, it is still unclear why CAR T- cells have an affinity for the CNS in the absence of disease. It has been demonstrated that endothelial activation and disruption of the blood-brain barrier likely support CAR T- cell trafficking and neurologic toxicity [43]. In the non-human 
primate model of CAR T-cell therapy, neurotoxicities have been reported to be associated with elevated levels of IL-6, inteleukin-12 (IL-12), granulocyte-macrophage colony-stimulating factor (GM-CSF), and vascular endothelial growth factor (VEGF), as well as both CAR and non-CAR T- cell accumulation in the CSF and brain parenchyma $[46,47]$.

\section{Clinical Presentations}

After anti-CD19 CAR T-cell therapy, neurological adverse events may occur in up to two-thirds of patients $(21-64 \%)[10,42,43]$. The severity of symptom manifestation correlates with CAR T-cell infusion dose, the extent of cell expansion in vivo, and the amount of tumour burden [48,49]. Neurologic adverse events (AEs) have been described in patients with CRS or upon its resolution, although mild neurologic symptoms may rarely occur in patients who never experienced CRS, and these are not considered to be a part of the neurotoxicity syndrome.

Neurologic AEs were further investigated in 133 adults with refractory B-ALL, NHL, or CLL who received lymphodepletion chemotherapy followed by infusion of CD19 CAR T-cells engineered to express a CD19specific CAR containing a 4-1BB costimulatory domain [43]. The onset of the neurotoxicity symptoms occurred within 28 days of anti-CD19 CAR T-cell infusion. Of the 133 patients, 53 (40\%) developed one or more grade $\geq 1$ neurologic AEs presenting within a median of four days after infusion of the CAR T-cells.

Manifestations of neurologic symptoms following CAR T-cell infusion can vary widely and range from headaches to encephalopathy. This encephalopathy syndrome initially presents with tremor, dysgraphia, mild expressive aphasia (impaired naming), impaired attention, apraxia, and mild lethargy. In more severe cases, focal neurological deficits can develop and progress in hours or days to global aphasia, generalized tonic/clonic seizures, motor weakness, incontinence, mental obtundation, and increased intracranial pressure. In very severe cases, coma, intracranial haemorrhage, and a fatal rapid-onset diffuse cerebral oedema can result $[10,42,46]$. Deaths have been reported from rapid-onset diffuse cerebral oedema, and brain autopsies have detected signs of endothelial activation and blood-brain barrier disruption.

Brain magnetic resonance imaging (MRI) may identify acute abnormalities including vasogenic oedema, leptomeningeal enhancement, and/or multifocal microhaemorrhages. Electroencephalography typically demonstrates diffuse slowing, although seizures or status epilepticus can occur.

To provide a uniform approach to the grading of neurotoxicity across trials and institutions, in June 2018, the American Society for Blood and Marrow Transplantation published the ASBMT consensus grading system for CSR and neurological toxicity (which they termed as immune effector cell-associated neurotoxicity syndrome, ICANS). Later, the CAR T-cell-therapy-associated toxicity (CARTOX 10) working group proposed a new grading system, which they termed CAR T-cell-related encephalopathy syndrome, CRES (Table 3) [35]. Both groups recommended four grades of severity for grading neurotoxicity based on logical requirements in assessing five neurological symptoms. However, the most crucial indicator that the universal grading still may not currently be feasible is that different CAR constructs and $\mathrm{T}$ cell manufacturing processes are associated with different rates of toxicity and manifestations [42]. 
Table 3. Grading and Management of CAR T-Cell Induced Neurotoxicity; Comparison of Two Scales ICANS and CRES

\begin{tabular}{|c|c|c|c|}
\hline $\begin{array}{l}\text { Neurotoxicity } \\
\text { Grade }\end{array}$ & Defining Features of Grade ICANS & Defining Features of Grade CRES & Management \\
\hline Grade 1 & $\begin{array}{l}\text { ICE score } 7-9 \text { and/or depressed level of } \\
\text { consciousness but awakens spontaneously } \\
\text { No seizures, motor weakness, or raised } \\
\text { ICP/cerebral edema }\end{array}$ & $\begin{array}{l}\text { Neurological assessment score (by } \\
\text { CARTOX-10*): } 7-9 \text { (mild impairment) } \\
\text { Raised intracranial pressure: NA } \\
\text { Seizures or motor weakness: NA }\end{array}$ & $\begin{array}{l}\text { I/V Hydration and supportive care } \\
\text { EEG/MRI } \\
\text { Seizure prophylaxis with levetiracetam } \\
\text { Neurology consultation } \\
\text { Consider tocilizumab if there is CRS } \\
\text { concurrent }\end{array}$ \\
\hline Grade 2 & $\begin{array}{l}\text { ICE score 3-6 and/or depressed level of } \\
\text { consciousness but awakens to voice } \\
\text { No seizures, motor weakness, or raised } \\
\text { ICP/cerebral edema }\end{array}$ & $\begin{array}{l}\text { Neurological assessment score (by } \\
\text { CARTOX-10*): } 3-6 \text { (moderate } \\
\text { impairment) } \\
\text { Raised intracranial pressure: NA } \\
\text { Seizures or motor weakness: NA }\end{array}$ & $\begin{array}{l}\text { Supportive care as in grade } 1 \\
\text { Consider low doses of steroids } \\
\text { (dexamethasone } 10 \mathrm{mg} \text { ) } \\
\text { Consider ICU transfer } \\
\text { Consider antiepileptic drug, if not started }\end{array}$ \\
\hline Grade 3 & $\begin{array}{l}\text { ICE score } 0-2 \text { and/or depressed level of } \\
\text { consciousness but awakens to tactile } \\
\text { stimulus } \\
\text { Any clinical seizure focal or generalized } \\
\text { that resolves rapidly, or nonconvulsive } \\
\text { seizures on EEG that resolve with } \\
\text { intervention } \\
\text { No motor weakness } \\
\text { Focal/local edema on neuroimaging }\end{array}$ & $\begin{array}{l}\text { Neurological assessment score (by } \\
\text { CARTOX-10*): } 0-2 \text { (severe impairment) } \\
\text { Raised intracranial pressure: Stage 1-2 } \\
\text { papilloedema }+ \text {, or CSF opening pressure } \\
<20 \mathrm{mmHg} \\
\text { Seizures or motor weakness: Partial } \\
\text { seizure, or non-convulsive seizures on } \\
\text { EEG with response to benzodiazepine }\end{array}$ & $\begin{array}{l}\text { Supportive care as grade } 2 \\
\text { ICU transfer } \\
\text { Continuous steroids: Dexamethasone } 10 \text { - } \\
20 \text { mg IV q } 6 \text { hours or its equivalent of } \\
\text { Methylprednisolone, High-dose } \\
\text { methylprednisolone } 1000 \mathrm{mg} / \text { day for } \\
\text { focal/local edema } \\
\text { Control seizures with benzodiazepines } \\
\text { (for short-term control) and } \\
\text { levetiracetam }+/- \text { phenobarbital and/or } \\
\text { lacosamide } \\
\text { Repeat MRI }\end{array}$ \\
\hline Grade 4 & $\begin{array}{l}\text { ICE score } 0 \text { and patient is unarousable or } \\
\text { requires vigorous or repetitive tactile } \\
\text { stimuli to arouse or stupor or coma } \\
\text { Life-threatening prolonged seizure } \\
(>5 \text { min); or repetitive clinical or } \\
\text { electrical seizures without return to } \\
\text { baseline in between } \\
\text { Deep focal motor weakness such as } \\
\text { hemiparesis or paraparesis } \\
\text { Diffuse cerebral edema on neuroimaging; } \\
\text { decerebrate or decorticate posturing; or } \\
\text { cranial nerve VI palsy; or papilledema; or } \\
\text { Cushing's triad }\end{array}$ & $\begin{array}{l}\text { Neurological assessment score (by } \\
\text { CARTOX-10*): Patient in critical } \\
\text { condition, and/or obtunded and cannot } \\
\text { perform assessment of tasks } \\
\text { Raised intracranial pressure: Stage } 3-5 \\
\text { papilloedemat, or CSF opening pressure } \\
\geq 20 \mathrm{mmHg} \text { or cerebral oedema } \\
\text { Seizures or motor weakness: Generalized } \\
\text { seizures, or convulsive or non-convulsive } \\
\text { status epilepticus, or new motor weakness }\end{array}$ & $\begin{array}{l}\text { Supportive care as grade } 3 \\
\text { High-dose methylprednisolone } 1000 \\
\text { mg/day } \\
\text { Control seizures with benzodiazepines } \\
\text { (for short-term control) and } \\
\text { levetiracetam }+/- \text { phenobarbital and/or } \\
\text { lacosamide } \\
\text { Imaging of spine for focal motor } \\
\text { weakness } \\
\text { Lower ICP by hyperventilation, } \\
\text { hyperosmolar therapy with } \\
\text { mannitol/hypertonic saline, and/or } \\
\text { neurosurgery consultation for } \\
\text { ventriculoperitoneal shunt in patients } \\
\text { with cerebral edema } \\
\text { Consider further individual treatment }\end{array}$ \\
\hline
\end{tabular}

CAR, chimeric antigen receptor; CARTOX 10, CAR T- cell-therapy-associated toxicity 10 points neurological assessment CSF, cerebrospinal fluid; EEG, electroencephalogram; NA, not applicable.

*In the CARTOX 10, one point is assigned for each of the following tasks that are performed correctly (normal cognitive function is defined by an overall score of 10): orientation to year, month, city, hospital, and President/Prime Minister of the country of residence (total of 5 points); name three objects - for example, point to clock, pen, button (maximum of 3 points); write a standard sentence, for example, 'our national bird is the bald eagle' (1 point); count backwards from 100 in tens (1 point). †Papilloedema grading is performed according to the modified Frisén scale (53).

\section{Treatment}

In most patients, CAR T-cell-induced neurotoxicity is completely reversible and tends to have a self-limited course. CARTOX 10 proposed a three-step approach for the assessment and management of acute toxicities associated with CAR T-cell therapy. Essential components of toxicity management include baseline patient assessments, early detection of toxicities, and prompt intervention to prevent catastrophic sequelae after CAR T-cell therapy. Due to the limited understanding of ICANS pathophysiology, management is primarily based 
on a grading system that recommends supportive care for low-grade toxicity and corticosteroids for more severe grades with escalating doses depending on severity of the ICANS. Admission to the intensive care unit should be considered for patients who develop severe ICANS (grade $\geq 2$ ) [50]. Most patients respond to steroids, although the median time to the resolution of symptoms is longer for ICANS (median nine days, range 4-21 days) than for CRS [46]. It is recommended to start treatment with 10mg dexamethasone every 6 hours until the symptoms resolve. In cases of high-grade toxicity (grade 4), high doses of methylprednisolone (e.g., 1000mg every 24 hours) should be administered.

Levetiracetam is routinely administered as a seizure prophylaxis and severe symptoms are treated with a short course of corticosteroids. Given the mechanism of action of tocilizumab, it is possible that blocking IL-6Rs may lead to increased serum levels and permeation into the CNS, increasing the risk of CNS toxicity, especially if concurrent CRS is present. This hypothesis suggests that for patients who are at a greater risk of complications from neurotoxicity, siltuximab (anti-IL-6 chimeric monoclonal antibody) may be preferred due to its direct effect on circulating IL-6 [48]. When considering antiepileptic prophylaxis, some patients in the ZUMA-1 trial showed no EEG proven seizure activity, and therefore no significant benefit for prophylactic levetiracetam has been demonstrated [46,51]. There is no clinical evidence to recommend additional treatment for patients who are unresponsive to high-dose steroid therapy.

\section{OTHER TOXICITIES BEYOND CRS AND ICANS}

Cellular therapy is complex and one of the challenges that occur post-CAR T-cell infusion is the differential diagnosis between overlapping symptoms in patients with a dysregulated immune response [50]. The significant immunosuppression due to conditioning chemotherapy, underlying malignancy, [68] and prolonged cytopenias pose a significant risk of infection and sepsis, including febrile neutropenia observed in patients after CAR T-cell infusion [69] and potentially concurrent with CRS. Grade $\geq 3$ neutropenia, anaemia and thrombocytopenia may persist beyond the first months after infusion of marketed CAR T-cell. Bacterial infections, especially bacteraemia, and viral infections, are the most common events of cytopenia [10,52]. The cytopenia has a bimodal pattern, and the risk associated with early cytopenias is the lymphodepleting chemotherapy, whereas for delayed cytopenias, it is severe CRS [76]. Cytopenia beyond the third month has been described in $16 \%$ of patients [29], and infections in the upper and lower respiratory tract infections may occur.

Hyperactivation of macrophages and the cytokine storm underlying macrophage activation syndrome (MAS) or hemophagocytic lymphohistiocytosis (HLH) can be triggered after CAR T-cell infusion [50]. The diagnosis of CAR T-cell related HLH/MAS can be based on ferritin pick levels of $>10,000 \mathrm{ng} / \mathrm{ml}$ during the CRS phase (typically within the first five days after cell infusion), along with grade $\geq 3$ organ toxicities involving the liver, kidney, or lung, or haemophagocytosis in the bone marrow or other organs. Approximately $1 \%$ of patients presenting with more severe forms of CRS will require additional treatment after 48 hours if there is an insufficient response to tocilizumab, etoposide [10] or with targetable agents for refractory HLH/MAS such as anti-IL-1R, anakinra. Other possible therapies include the anti-CD52 antibody alemtuzumab, off-label use of the JAK2 inhibitor ruxolitinib, anti-IFN- $\gamma$ emapalumab among others [70]. The guidelines of the American Society for Transplantation and Cellular Therapy do not separate CRS from HLH/MAS, and it is not graded separately [27].

Coagulation abnormalities were described when using commercially available products [71]. Another study reported elevated D-dimer, increased fibrinogen degradation product, decreased fibrinogen, prolonged activated partial thromboplastin time and prolonged prothrombin time (mainly day 6-20) in the context of CRS after treatment with self-manufactured anti-CD 19 CAR T-cell therapy [72]. Recently, a centre has reported a significant incidence $(11 \%)$ of venous thromboembolism in patients treated with CAR T-cell therapies for large B-cell lymphoma [76]. These patients could be safely managed with anticoagulation without bleeding events. Hypofibrinogenemia was observed without major bleeding events. Some patients 
were treated with cryoprecipitate to correct fibrinogen levels, but it is not clear if this provides therapeutic benefit.

Anti-CD19 CAR T-cells cause B-cell aplasia and hypogammaglobulinemia [3], which eventually resolves in most cases [29]. The hypogammaglobulinemia may recover within two years post-infusion [8]. In the TRANSCEND trial, hypogammaglobulinemia was reported as an adverse reaction in 14\% (37/268) of patients receiving treatment with lisocabtagene maraleucel. Laboratory $\mathrm{IgG}$ levels fell below $500 \mathrm{mg} / \mathrm{dL}$ after infusion in $21 \%(56 / 268)$ of patients. Therefore, the recommendations are to monitor immunoglobulin levels after treatment and to use infection precautions, antibiotic prophylaxis, and immunoglobulin replacement as clinically indicated $[41,78]$.

In some cases, B-cell aplasia can lead to HBV reactivation, resulting in fulminant hepatitis, hepatic failure, and death. Therefore, HBV, HCV, and HIV screening should be performed prior to CAR T-cell therapy [69].

A total of 101 infectious complications were reported in 60 patients with diffuse large B-cell lymphoma (DLBCL) treated with commercially available Kymriah® and Yescarta® from Memorial Sloan Kettering Cancer Center (MSKCC) [73]. Their incidence of overall infection was comparable to other pivotal studies. Bacterial infections were the most frequent $(63.3 \%)$, predominantly with upper respiratory tract infections. Prophylactic antimicrobials against bacterial and/or fungal infections in patients with prolonged grade 4 neutropenia should be considered [10] and prophylaxis against herpes zoster and pneumocystis jiroveci pneumonia is recommended for at least one year [29,51]. Infusion reactions are usually infrequent and mild, caused by the contents of dimethyl sulfoxide (DMSO) as a cryoprotectant. Patients treated with CAR T-cell therapies should be monitored life-long for secondary malignancies [69].

In addition to CAR T-infusion toxicities, conditioning regimens with fludarabine and cyclophosphamide can lead to the development of anaemia, thrombocytopenia, and neutropenia. Prolonged duration of cytopenias is possible $[68,71]$. The aetiology of prolonged cytopenias post-CAR T-cell therapy is unclear but is likely related to ongoing CAR T-cell activity and disruption of haematopoiesis since bone marrow examination frequently shows severe hypocellularity. This can be managed with growth factor support for neutropenia and transfusion support [41]. From the MSKCC report, 94 recurrent cytopenic events were observed in 38 patients (grade $\geq 3$; n33). Leukopenia with neutropenia was the most common cytopenia $(70 \%)$ followed by thrombocytopenia $(56.7 \%)$ and anaemia $(46.7 \%)$. Most $(90.4 \%)$ persistent/delayed-onset cytopenias occurred between day +31 and +180 post-CAR T-cell infusion [71]. In the two-year follow-up data from ZUMA-1, a pivotal study for the approval of axicabtagene xiloleucel, less than $20 \%$ of patients had grade 3 or worse cytopenias three months after treatment, and none had major bleeding or required allogeneic stem cell transplantation to correct these [29].

CAR T-cell therapy and CRS can cause several cardiovascular toxicities. Two mechanisms, direct and indirect, have been proposed to explain cardiac events. The direct mechanism is thought to be mediated by the release of cytokines and effects on the cardiovascular system leading to hypotension and tachycardia (the most common side effects) and progressing to instability and shock in the most severe cases [68,71]. Arrhythmias have been reported mostly in the context of CRS. The most common abnormalities found in these patients are asymptomatic prolonged QTc interval and atrial fibrillation. Hypotension has been reported in up to one-third of patients with CRS [75]. The other reported cardiac toxicities include an increase in serum troponins and a decrease in left ventricular systolic function. The resulting ventricular dysfunction may be related to a release of tumour necrosis factor-a, which may decrease myocyte shortening and mitochondrial dysfunction [75]. CAR T-cell therapy can be used to achieve remission before allogeneic stem cell transplant; therefore, the reversibility of end-organ toxicities is very important [68]. Table 4 summarises the most common significant adverse events. 
Table 4. Summary of Adverse Events of Special Interest (AESI) of the Marketed Anti-CD19 CAR T-Cell Therapies

\begin{tabular}{|c|c|c|c|c|c|c|c|c|}
\hline \multirow[t]{2}{*}{$\begin{array}{l}\text { Adverse Event of Special Interest } \\
\text { (AESI) }\end{array}$} & \multicolumn{2}{|c|}{\begin{tabular}{|l|} 
Axicabtagene ciloleucel \\
(Yescarta)* \\
$\mathrm{N}=108$
\end{tabular}} & \multicolumn{2}{|c|}{$\begin{array}{l}\text { Tisagenlecleucel } \\
(\text { Kymriah)* } \\
\mathbf{N}=68\end{array}$} & \multicolumn{2}{|c|}{$\begin{array}{l}\text { Brexucabtagene autoleucel } \\
\text { (Tecartus) }^{\star} \\
\mathrm{N}=\mathbf{8 2}\end{array}$} & \multicolumn{2}{|c|}{$\begin{array}{l}\text { Lisocabtagene maraleucel } \\
\text { (Brexanzi) [77] } \\
\mathrm{N}=\mathbf{2 6 9}\end{array}$} \\
\hline & All Grades & Grade $\geq 3$ & All Grades & Grade $\geq 3$ & All Grades & Grade $\geq 3$ & All Grades & Grade $\geq 3$ \\
\hline $\begin{array}{l}\text { Neurotoxicity } \\
\text { Encephalopathy } \\
\text { Headache } \\
\text { Tremor } \\
\text { Dizziness } \\
\text { Aphasia/ dysphasia } \\
\text { Delirium } \\
\text { Insomnia } \\
\text { Anxietx }\end{array}$ & $\begin{array}{c}94(87 \%) \\
62(57 \%) \\
49(45 \%) \\
34(31 \%) \\
22(20 \%) \\
19(18 \%) \\
18(17 \%) \\
15(14 \%) \\
12(11 \%)\end{array}$ & $\begin{array}{l}34(31 \%) \\
31(29 \%) \\
1(1 \%) \\
2(2 \%) \\
- \\
7(6 \%) \\
7(6 \%) \\
- \\
1(1 \%)\end{array}$ & $\begin{array}{l}\mathbf{4 4}(\mathbf{6 5} \%) \\
23(34 \%) \\
25(37 \%) \\
6(9 \%) \\
4(6 \%) \\
2(3 \%) \\
14(21 \%) \\
4(6 \%) \\
9(13 \%)\end{array}$ & $\begin{array}{l}12(18 \%) \\
6(9 \%) \\
1(1 \%) \\
- \\
- \\
1(1 \%) \\
3(4 \%) \\
- \\
2(3 \%)\end{array}$ & $\begin{array}{l}66(81 \%) \\
41(50 \%) \\
29(35 \%) \\
31(38 \%) \\
14(16 \%) \\
19(23 \%) \\
13(16 \%) \\
- \\
14(17 \%)\end{array}$ & $\begin{array}{l}30(37 \%) \\
19(23 \%) \\
1(1 \%) \\
2(2 \%) \\
2(2 \%) \\
7(9 \%) \\
4(5 \%) \\
- \\
-\end{array}$ & $\begin{array}{l}\mathbf{8 0}(\mathbf{3 0} \%) \\
57(21 \%) \\
9(3 \%) \\
26(10 \%) \\
11(4 \%) \\
26(10 \%) \\
16(6 \%) \\
36(13 \%) \\
27(10 \%)\end{array}$ & $\begin{array}{l}27(10 \%) \\
18(7 \%) \\
2(1 \%) \\
0 \\
2(1 \%) \\
5(2 \%) \\
4(1 \%) \\
1(<1 \%) \\
0\end{array}$ \\
\hline $\begin{array}{l}\text { Infection } \\
\text { Infections pathogen unspecified } \\
\text { Viral infection } \\
\text { Bacterial infection } \\
\text { Pneumoniae/Lung infection } \\
\text { Fungal infection }\end{array}$ & \begin{tabular}{l|}
$\mathbf{4 3}(\mathbf{4 0} \%)$ \\
$28(26 \%)$ \\
$17(16 \%)$ \\
$14(13 \%)$ \\
$13(12 \%)$ \\
$5(5 \%)$ \\
\end{tabular} & $\begin{array}{l}25(23 \%) \\
1716 \%) \\
4(4 \%) \\
10(9 \%) \\
11(10 \%) \\
0 \\
\end{array}$ & $\begin{array}{l}40(59 \%) \\
- \\
- \\
- \\
- \\
9(13 \%) \\
\end{array}$ & $\begin{array}{l}19(27 \%) \\
- \\
- \\
- \\
- \\
5(7 \%) \\
\end{array}$ & $\begin{array}{l}47(57 \%) \\
35(43 \%) \\
14(17 \%) \\
13(16 \%) \\
15(17 \%) \\
8(10 \%) \\
\end{array}$ & $\begin{array}{l}26(32 \%) \\
23(28 \%) \\
4(5 \%) \\
6(7 \%) \\
10(12 \%) \\
0 \\
\end{array}$ & $\begin{array}{l}\mathbf{1 2 1}(\mathbf{4 5} \%) \\
16 \% \\
1.5 \% \\
5 \% \\
- \\
0.4 \% \\
\end{array}$ & $\begin{array}{l}88(19 \%) \\
- \\
- \\
- \\
- \\
- \\
\end{array}$ \\
\hline $\begin{array}{l}\text { Cardiac disorders } \\
\text { Heart Failure } \\
\text { Tachycardia } \\
\text { Bradycardia } \\
\text { Arrhythmia } \\
\text { Pulmonarx edema }\end{array}$ & \begin{tabular}{|l|}
$\mathbf{7 4}(69 \%)$ \\
$3(3 \%)$ \\
$62(57 \%)$ \\
$7(6 \%)$ \\
$23(21 \%)$ \\
$10(9 \%)$ \\
\end{tabular} & \begin{tabular}{|l|}
$14(13 \%)$ \\
$3(3 \%)$ \\
$2(2 \%)$ \\
- \\
$6(6 \%)$ \\
$3(3 \%)$ \\
\end{tabular} & \begin{tabular}{l|}
$22(32 \%)$ \\
$5(22 \%)$ \\
$18(81 \%)$ \\
$4(18 \%)$ \\
- \\
- \\
\end{tabular} & $\begin{array}{l}4(6 \%) \\
1 \\
- \\
- \\
- \\
- \\
\end{array}$ & \begin{tabular}{|l|}
$60(73 \%)$ \\
$1(1 \%)$ \\
$38(46 \%)$ \\
- \\
$18(22 \%)$ \\
- \\
\end{tabular} & \begin{tabular}{|l|}
$\mathbf{1 5}(18 \%)$ \\
$1(1 \%)$ \\
- \\
- \\
$8(10 \%)$ \\
- \\
\end{tabular} & \begin{tabular}{|l|}
$\mathbf{8 0}(\mathbf{3 0} \%)$ \\
- \\
$25 \%$ \\
- \\
$6 \%$ \\
- \\
\end{tabular} & $\begin{array}{l}- \\
- \\
0 \\
- \\
- \\
- \\
\end{array}$ \\
\hline Renal insufficiency & $13(12 \%)$ & $5(5 \%)$ & $14(21 \%)$ & $8(12 \%)$ & $10(12 \%)$ & $6(7 \%)$ & $29(11 \%)$ & $8(3 \%)$ \\
\hline Hypogammaglobulinemia & $16(15 \%)$ & 0 & $20(29 \%)$ & $3(4 \%)$ & $12(15 \%)$ & $1(1 \%)$ & $37(14 \%)$ & 0 \\
\hline $\begin{array}{l}\text { Blood and lymphatic system disorders } \\
\text { Neutropenia } \\
\text { Anemia } \\
\text { Thrombocytopenia } \\
\text { Leukopenia } \\
\text { Lymphopenia } \\
\text { Febrile Neutropenia }\end{array}$ & $\begin{array}{l}86(80 \%) \\
63(58 \%) \\
59(55 \%) \\
46(43 \%) \\
23(21 \%) \\
-(36 \%) \\
\end{array}$ & $\begin{array}{l}79(73 \%) \\
46(43 \%) \\
42(39 \%) \\
43(40 \%) \\
22(20 \%) \\
-(32 \%) \\
\end{array}$ & $\begin{array}{l}- \\
21(31 \%) \\
39(57 \%) \\
14(21 \%) \\
- \\
-\end{array}$ & $\begin{array}{l}- \\
9(13 \%) \\
17(25 \%) \\
- \\
- \\
14(21 \%)\end{array}$ & $\begin{array}{l}71(87 \%) \\
53(65 \%) \\
57(70 \%) \\
48(59 \%) \\
17(21 \%) \\
-(6 \%) \\
\end{array}$ & $\begin{array}{l}70(85 \%) \\
40(49 \%) \\
31(50 \%) \\
47(57 \%) \\
14(17 \%) \\
- \\
\end{array}$ & $\begin{array}{l}169(63 \%) \\
129(48 \%) \\
- \\
- \\
- \\
25(9 \%) \\
\end{array}$ & $\begin{array}{l}161(60 \%) \\
101(37 \%) \\
72(27 \%) \\
- \\
- \\
24(9 \%) \\
\end{array}$ \\
\hline Prolonged cxtopenia $\geq 28$ days & - & $30(28 \%)$ & $36(53 \%)$ & $25(37 \%)$ & - & $46(56 \%)$ & $100(37 \%)$ & - \\
\hline Bleeding Risk & NR & NR & $27(40 \%)$ & $12(18 \%)$ & NR & NR & NR & NR \\
\hline Secondarx malignancies & 0 & 0 & 0 & 0 & 0 & 0 & NR & NR \\
\hline
\end{tabular}

$\mathrm{R} / \mathrm{R}=$ refractory/relapsed; $\mathrm{NR}=$ not reported

* Data provided based on Biologics License Applications (BLA) to the FDA

Note: Kymriah is approved for adult patients with R/R B-cell lymphomas after two or more lines of systemic therapy and patients up to 25 years of age with multiple R/R B-cell precursor acute lymphoblastic leukaemia (ALL). Tecartus is approved for the treatment of adult patients with relapsed or refractory mantle cell lymphoma. Jescarta is approved for the treatment of adult patients with relapsed/refractory B-cell lymphomas after two or more lines of systemic therapy. Brexanzi is approved for adult patients with R/R B-cell lymphomas after two or more lines of systemic therapy

\section{RISK FACTORS RELATED TO CAR T-CELL THERAPY}

CRS and CNS toxicity should be considered as two related side effects as they overlap, resulting from excessive immune activation. The severity of neurotoxicity and CRS indicators correlate with increased expansion of CAR T-cells. Neurologic toxicity can occur at the same time as CRS, but in some instances, it could be before CRS or days later [43,46]. A higher neurologic toxicity grade has been shown to be associated with higher grade CRS $[33,46]$. In terms of CAR T-cell infusion-specific factors, the infused CAR T-cell dose and conditioning lymphodepletion are factors associated with severe CSR and CNS toxicities $[11,26,33,43,55,56]$. Multiple chemotherapy regimens have been used in CAR T-cell trials, and clinical results suggest that massive lymphodepletion can increase specific cytokines, such as interleukin-15, and depletion of T regulatory cells and subsequently the enhancement of CAR T-cell activity in humans [57, 58].

In terms of patient-specific factors like higher disease burden, baseline thrombocytopenia, and baseline elevated markers of endothelial activation, such as angiopoietin-2 (ANG2) and von Willebrand factor, have been associated with the development of severe CRS and severe neurotoxicity [59]. Disease burden is associated with a peak increase in the number of CAR T cells in vivo [50,61], which should be the main pathway for the occurrence and severity of CRS and CNS toxicity. Disease burden was a constant risk factor for CRS $[43,62,63]$ as well as for CNS toxicity [11, 64,66] after CAR T-cell infusion. The risk of severe CRS increased in patients with comorbidities and in those who develop the syndrome within three days of infusion $[18,16]$. Pre-existing concomitant neurological diseases may be a risk factor for neurotoxicity. Also, neurotoxicity is more common in younger patients and not highly pre-treated patients [11]. Children are at higher risk of developing CRS than adults. In paediatric ALL patients, the incidence of CRS after infusion of anti-CD19 targeted CAR T-cells is high, as shown in two clinical studies that tested different 19-targeted CAR constructs [26,36]. The reasons for the higher incidence of CRS in paediatric patients are unknown. There is an active field of research working to identify various cytokines and chemokines as potential biomarkers for 
predicting which patients are likely to develop severe CAR T-cell-related toxicities before they become critically ill.

\section{CAR T-CELL THERAPY-RELATED DEATHS}

Treatment-related deaths continue to be a critical issue in CAR T-cell therapy. A retrospective search of the FDA adverse events reporting system (FAERS) [16] identified a 15\% non-relapse mortality (NRM) for the entire cohort and $21 \%$ for patients treated with tisagenlecleucel and $10 \%$ for axicabtagene ciloleucel. $56 \%$ of patients treated with axicabtagene ciloleucel died from neurotoxicity, 53\% from CRS, and 44\% from infectious complications. With tisagenlecleucel, $56 \%$ had infectious complications that led to death, $46 \%$ of deaths were due to neurotoxicity, $46 \%$ haematological toxicities, $47 \%$ cardiovascular toxicities, and $41 \%$ renal complications. Later, the same group reported at the ASH Meeting 2019 that there was 7\% NRM in a new FAERS search that included 1083 patients receiving either tisagenlecleucel or axicabtagene ciloleucel. The proportion of 30-day NRM with ZUMA-1 was 3\% [29]. In the ZUMA-1 study, there were two treatmentrelated deaths. One death was due to HLH and the other was due to cardiac arrest. In the two-year follow-up, no new treatment-related deaths occurred [33]. In the MSKCC cohort, the most common cause of death was disease progression. Two patients (3.3\%) died in remission, one due to severe influenza pneumonia (at five months) and one due to extensive hepatic vein thrombosis (at one year) [71]. Correctly detecting, classifying, and treating the significant toxicities related to CAR T-cells will help reduce mortality in this patient population.

\section{FUTURE DIRECTIONS}

Anti-CD19 CAR T-cell therapies offer the promise to improve clinical outcomes and induce complete remissions in patients with haematological malignancies; however, the acute toxicity of such therapies, which can be fatal, requires intensive monitoring and prompt management. Many factors related to CAR T-cell therapy are considered to contribute to the development of toxicities such as the conditioning chemotherapy and the design, construct and dose of CAR T- cells. At the patient level, factors such as the type of malignancy, tumour burden, and age are also factors that play a role in the development of adverse events. Systematic investigations are still necessary to define predictors of toxicity and develop effective prophylaxis therapies. There is robust evidence that serum levels of cytokines and chemokines, which have direct implications in CSR, CNS toxicity, flu-like events, diarrhoea, cardiomyopathy and others are positively correlated with the severity of symptoms. In this context, further investigations that seek to abate post-infusion CAR T-cell related effects are essential for managing severe events in the future. However, there is a concern that blocking these cytokines and chemokines will potentially affect antitumour efficacy. The eventual use of rituximab for CD20 expressing CAR T- cells may also be another alternative, but with the same concerns regarding the impact on efficacy. The currently available IL-6 antagonists are not expected to cross the blood-brain barrier; however, investigation of intrathecal administration of these agents is warranted for the management of CNS toxicities. Another approach that is currently being tested in preclinical and clinical studies to improve safety is "suicide genes," such as inducible caspase 9, to induce rapid apoptosis in order to eliminate CAR T-cells when life-threatening toxicities develop. Another potential alternative strategy is to use "remote-controlled" CARs, whereby an inducible gene-regulatory system enables controlled expression of CARs upon drug administration. Due to potential nullification of the CAR T-cells, approaches with mainly permanent treatments are not optimal; thus, reversible approaches are desirable.

Dasatinib, an approved tyrosine kinase inhibitor, has the characteristic of temporary suppression of T-cell activity by inhibiting the T-cell receptor signalling kinases used for signal transduction in CAR T-cells. The CAR T-cell antitoxic approach of dasatinib is being investigated in preclinical studies [74]. Several approaches are investigating extensively engineered CAR T-cells to enhance the safety of CAR T-cell therapies, or combing strategies with immune-checkpoint blockade, which have the potential to increase the antitumour activity and persistence of CAR T-cells, but may also increase their toxicity. Other factors, such as the omission of lymphoid-depleting chemotherapy and non-inclusion of supplementary IL-2 can be useful to lower toxicities. Currently, there are many ongoing clinical trials studying different alternative strategies to 
mitigate CSR and CNS toxicities. The concept "new medicine new adverse event" should apply to the novel transgenic CAR T-cells with an emphasis on close monitoring of unexpected or newly observed adverse events. The close monitoring of events is of extreme importance when evaluating any novel CAR T-cell or transgenic TCR-based therapy, including evaluations of novel conditioning regimens, novel CAR or TCR constructs, novel targets, and novel treatment combinations. Since the technology is being adapted in medical practice, telemedicine could be an excellent strategy for the early detection of events along with timely and tailored clinical decisions and treatments.

\section{CONCLUSION}

Since CAR T-cells are rapidly entering clinical practice, recognition of the clinical presentation, early identification, and appropriate monitoring of CAR T-cell-mediated adverse events, as well as prompt therapeutic intervention is vital for cancer patients with haematological diseases. Although there has been remarkable progress in the understanding of CAR T-cell-mediated immunotoxicity, there still is a lack of knowledge, especially in the field of CAR T-cell-related neurotoxicity. While anti-IL-6 prescription is a recognized therapy for CRS, neurotoxicity induced by CAR T-cells is still difficult to treat and may develop into a life-threatening situation for cancer patients. More preclinical and clinical studies are needed to further understand CAR T-cell-mediated immunotoxicity and to develop efficient treatments to abate these adverse effects.

\section{Acknowledgments}

Sincere gratitude to Professor Thomas Moehler for his comments and expert review.

\section{References}

[1] S. M. Hedrick, D. I. Cohen, E. A. Nielsen \& M. M. Davis. Isolation of cDNA clones encoding T cellspecific membrane-associated proteins. Nature, volume 308, pages 149-153(1984)

[2] Y. Yanagi, Y. Yoshikai, K. Leggett, S.P. Clark et al. A human T cell-specific cDNA clone encodes a protein having extensive homology to immunoglobulin chains. Nature, 308 (1984), pp. 145-149.

[3] Z. Eshhar, T. Waks, G. Gross, D.G. Schindler. Specific activation and targeting of cytotoxic lymphocytes through chimeric single chains consisting of antibody-binding domains and the gamma or zeta subunits of the immunoglobulin and T-cell receptors. Proc Natl Acad Sci USA, 1993 Jan 15;90(2):720-4. doi: 10.1073/pnas.90.2.720.

[4] J.N. Kochenderfer, S.A. Rosenberg. Treating B-cell cancer with T cells expressing anti-CD19 chimeric antigen receptors. Nat Rev Clin Oncol, 2013;10:267-76. [PubMed: 23546520] doi:

10.1038/nrclinonc.2013.46.

[5] M. Sadelain, R. Brentjens, I. Riviere. The basic principles of chimeric antigen receptor design. Cancer Discov. 2013 Apr;3(4):388-98. doi: 10.1158/2159-8290.CD-12-0548.

[6] M. Sadelain, I. Rivière, R. Brentjens, Targeting tumours with genetically enhanced T lymphocytes. Nat. Rev. Cancer 3, 35-45 (2003). doi: 10.1038/nrc971; pmid: 12509765

[7] M. Sadelain, R. Brentjens, I. Rivière, The basic principles of chimeric antigen receptor design. Cancer Discov. 3, 388-398 (2013). doi: 10.1158/2159-8290.CD-12-0548; pmid: 23550147

[8] Garfall, A. L., M. V. Maus, Wei-Ting Hwang, S. F. Lacey et al. Chimeric antigen receptor T cells against CD19 for multiple myeloma. New Engl. J. Med. 373, 1040-1047 (2015). DOI:

10.1056/NEJMoa1504542

[9] Grupp, S. A., Michael Kalos, D. Barrett, R. Aplenc, David L. Porter et al. Chimeric antigen receptormodified T cells for acute lymphoid leukemia. New Engl. J. Med. 368, 1509-1518 (2013). DOI:

10.1056/NEJMoa1215134

[10] Neelapu, S. S., Frederick L. Locke, N. L. Bartlett, L. J. Lekakis, D. B. Miklos, Caron A et al. Axicabtagene ciloleucel CAR T-cell therapy in refractory large B-cell lymphoma. New Engl. J. Med. 377, 2531-2544 (2017). DOI: 10.1056/NEJMoa1707447

[11] Lee, D. W., D. W Lee, J. N Kochenderfer, M. Stetler-Stevenson, Yongzhi K Cui, Cindy Delbrook , Steven A Feldman, Terry J Fry et al. T cells expressing CD19 chimeric antigen receptors for acute 
lymphoblastic leukaemia in children and young adults: a phase 1 dose escalation trial. Lancet 385, 517-528 (2015). DOI: 10.1016/S0140-6736(14)61403-3

[12] Brentjens, R. J. , Marco L Davila, Isabelle Riviere, Jae Park, Xiuyan Wang, Lindsay G Cowell, et al. CD19-targeted T cells rapidly induce molecular remissions in adults with chemotherapy-refractory acute lymphoblastic leukemia. Sci Transl Med. 2013 Mar 20;5(177):177ra38. doi: 10.1126/scitranslmed.3005930. [13] FDA approval brings first gene therapy to the United States: CAR T-cell therapy approved to treat certain children and young adults with B-cell acute lymphoblastic leukemia.

https://www.fda.gov/NewsEvents/Newsroom/PressAnnouncements/ucm574058.htm. United States Food and Drug Administration Press ReleaseAugust 30, 2017.

[14] FDA approves CAR-T cell therapy to treat adults with certain types of large B-cell lymphoma: Yescarta is the second gene therapy product approved in the U.S

https://www.fda.gov/NewsEvents/Newsroom/PressAnnouncements/ucm581216.htm. United States Food and Drug Administration Press ReleaseOctober 18, 2017.

[15] FDA approves tisagenlecleucel for adults with relapsed or refractory large B-cell lymphoma. https://www.fda.gov/Drugs/InformationOnDrugs/ApprovedDrugs/ucm606540.htm. United States Food and Drug Administration Press Release May 1, 2018.

[16] FDA Approves First Cell-Based Gene Therapy For Adult Patients with Relapsed or Refractory MCL. https://www.fda.gov/news-events/press-announcements/fda-approves-first-cell-based-gene-therapy-adultpatients-relapsed-or-refractory-mcl. United States Food and Drug Administration Press Release July 24, 2020.

[17] FDA Approves New Treatment For Adults With Relapsed Or Refractory Large-B-Cell Lymphoma. https://www.fda.gov/news-events/press-announcements/fda-approves-new-treatment-adults-relapsed-orrefractory-large-b-cell-lymphoma. United States Food and Drug Administration Press Release February 05, 2021

[18] Lee DW, Gardner R, Porter DL, et al. Current concepts in the diagnosis and management of cytokine release syndrome. Blood. 2014;124:188-195. doi: 10.1182/blood-2014-05-552729.

[19] Shimabukuro-Vornhagen A., Godel P., Subklewe M, Stemmler HJ et al. Cytokine release syndrome. Journal for ImmunoTherapy of Cancer.2018; 6: 56-70. doi: 10.1186/s40425-018-0343-9.

[20] Matthys P, Dillen C, Proost P, Heremans H, Van Damme J, Billiau A. Modification of the anti-CD3induced cytokine release syndrome by anti-interferon-gamma or anti-interleukin-6 antibody treatment: protective effects and biphasic changes in blood cytokine levels. Eur J Immunol. 1993;23:2209-16.

DOI: $10.1002 /$ eji.1830230924

[21] Tanaka T, Narazaki M, Kishimoto T. Immunotherapeutic implications of IL-6 blockade for cytokine storm. Immunotherapy. 2016;8(8):959-70. DOI: 10.2217/imt-2016-0020

[22] Scheller, J., Chalaris, A., Schmidt-Arras, D. \& Rose-John, S. The pro-and anti-inflammatory properties of the cytokine interleukin-6. Biochim. Biophys. 2011; (1813): 878-888. doi:

10.1016/j.bbamcr.2011.01.034.

[23] Hunter CA, Jones SA. IL-6 as a keystone cytokine in health and disease. Nat Immunol. 2015;16:44857. doi: 10.1038/ni.3153.

[24] Kang S, Tanaka T, Inoue H, et al. IL-6 trans-signalling induces plasminogen activator inhibitor-1 from vascular endothelial cells in cytokine release syndrome. Proc Natl Acad Sci USA. 2020;117(36):2235122356. doi: 10.1073/pnas.2010229117.

[25] Teachey DT, Lacey SF, Shaw PA, Melenhorst JJ, Maude SL, Frey N, et al. Identification of predictive biomarkers for cytokine release syndrome after chimeric antigen receptor $\mathrm{T}$ cell therapy for acute lymphoblastic leukemia. Cancer Discov. 2016 (6):664-679. doi: 10.1158/2159-8290.CD-16-0040.

[26] Hay KA, Hanafi L-A, Li D, Gust J, Liles WC, Wurfel MM, et al. Kinetics and biomarkers of severe cytokine release syndrome after CD19 chimeric antigen receptor-modified T cell therapy. Blood. 2017. doi: 10.1182/blood-2017-06-793141.

[27] Lee DW, Santomasso BD, Locke FL, Armin Ghobadi, Cameron J Turtle et al. ASTCT consensus grading for cytokine release syndrome and neurologic toxicity associated with immune effector cells. Biol Blood Marrow Transplant. 2019; 25:625-638. doi: 10.1016/j.bbmt.2018.12.758. 
[28] Schuster SJ, Bishop MR, Tam C, et al. Sustained disease control for adult patients with relapsed or refractory diffuse large B-Cell lymphoma: an updated analysis of Juliet, a global pivotal phase 2 trial of tisagenlecleucel. Blood 2018; 132: 1684. doi.org/10.1182/blood-2018-99-115252

[29] Locke FL, Ghobadi A, Jacobson CA, et al. Long-term safety and activity of axicabtagene ciloleucel in refractory large B-cell lymphoma (ZUMA-1): a single-arm, multicentre, phase 1-2 trial. Lancet Oncol 2019; 20: 31-42. doi: 10.1016/S1470-2045(18)30864-7.

[30] Abramson JS, Gordon LI, Palomba ML, et al. Updated safety and long term clinical outcomes in TRANSCEND NHL 001, pivotal trial of lisocabtagene maraleucel (JCAR017) in R/R aggressive NHL. J Clin Oncol, abstract 7505. DOI: 10.1200/JCO.2018.36.15_suppl.7505

[31] Nastoupil LJ, Jain MD, Spiegel JY, Ghobadi A, Lin Y. Axicabtagene ciloleucel (axi-cel) CD19 chimeric antigen receptor (CAR) T-cell therapy for relapsed/refractory large B-cell lymphoma: real world experience. Blood. 2018; 132:91. doi.org/10.1182/blood-2018-99-114152

[32] Maude SL, Laetsch TW, Buechner J, S. Rives, M. Boyer et al. Tisagenlecleucel in children and young adults with B-cell lymphoblastic leukemia. N Engl J Med. 2018;378:439-448. DOI:

10.1056/NEJMoa1709866

[33] Gardner RA, Finney O, Annesley C, et al. Intent-to-treat leukemia remission by CD19 CAR T cells of defined formulation and dose in children and young adults. Blood. 2017;129:3322-3331. doi:

10.1182/blood-2017-02-769208.

[34] Park JH, Riviere I, Gonen M, et al. Long-term follow-up of CD19 CAR therapy in acute lymphoblastic leukemia. N Engl J Med. 2018;378:449-459. DOI: 10.1056/NEJMoa1709919

[35] Neelapu SS, Tummala S, Kebriaei P, et al. Chimeric antigen receptor T-cell therapy - assessment and management of toxicities. Nat Rev Clin Oncol. 2018;15:47-62. doi: 10.1038/nrclinonc.2017.148.

[36] Maude SL, Frey N, Shaw PA, et al. Chimeric antigen receptor T cells for sustained remissions in leukemia. N Engl J Med. 2014;371:1507-1517. DOI: 10.1056/NEJMoa1407222

[37] Si S, Teachey DT. Spotlight on Tocilizumab in the Treatment of CAR-T-Cell-Induced Cytokine

Release Syndrome: Clinical Evidence to Date. Ther Clin Risk Manag. 2020;16:705-714. Published 2020

Aug 4. doi:10.2147/TCRM.S223468

[38] Davila ML, Riviere I, Wang X, et al. Efficacy and toxicity management of 19-28z CAR T cell therapy

in B cell acute lymphoblastic leukemia. Sci Transl Med 2014; 6:224ra25. doi:

10.1126/scitranslmed.3008226.

[39] Chen F, Teachey DT, Pequignot E, et al. Measuring IL-6 and sIL-6R in serum from patients treated with tocilizumab and/or siltuximab following CAR T cell therapy. J Immunol Methods. 2016;434:1-8. doi: 10.1016/j.jim.2016.03.005.

[40] Sun Y, Wang F, Zhao L, zhang B et al. IFN- $\gamma$ and TNF- $\alpha$ aggravate endothelial damage caused by CD123-targeted CAR T cell. OncoTargets and Therapy 2019:12 4907-4925. doi: 10.2147/OTT.S205678

[41] Sattva S. Neelapu. Managing the toxicities of CAR T-cell therapy. Hematological Oncology.

2019;37(S1):48-52. Published: 12 June 2019. doi.org/10.1002/hon.2595

[42] Kevin A. Hay . Cytokine release syndrome and neurotoxicity after CD19 chimeric antigen receptormodified (CAR-) T cell therapy. British Journal of Haematology, 2018, 183, 364-374. first published: 08 November 2018. doi.org/10.1111/bjh.15644

[43] Juliane Gust, Kevin A Hay, Laïla-Aïcha Hanafi, et al. Endothelial Activation and Blood-Brain Barrier Disruption in Neurotoxicity after Adoptive Immunotherapy with CD19 CAR-T Cells. Cancer Discov. 2017 Dec;7(12):1404-1419. doi: 10.1158/2159-8290.CD-17-0698.

[44] Barbara Camisa, Giulia Barbiera et al. Monocyte-derived IL-1 and IL-6 are differentially required for cytokine-release syndrome and neurotoxicity due to CAR T cells. Nat Med. 2018 Jun;24(6):739-748. doi:

10.1038/s41591-018-0036-4.

[45] Singh, N., Hofmann, T.J., Gershenson, Z., et al. Monocyte lineage derived IL-6 does not affect chimeric antigen receptor T-cell function. Cytotherapy. 2017 July; 19(7): 867-880.

doi:10.1016/j.jcyt.2017.04.001.

[46] Bianca D. Santomasso, Jae H. Park, Darin Salloum et al. Clinical and Biological Correlates of Neurotoxicity Associated with CAR T-cell Therapy in Patients with B-cell Acute Lymphoblastic Leukemia. Cancer Discov. 2018 Aug;8(8):958-971. DOI: 10.1158/2159-8290.CD-17-1319 
[47] Taraseviciute A, Tkachev V, Ponce R, et al. Chimeric antigen receptor T cell-mediated neurotoxicity in non-human primates. Cancer Discov 2018;8:750-63. doi: 10.1158/2159-8290.CD-17-1368.

[48] David Sermer and Renier Brentjens. CAR T-cell therapy: Full speed ahead. Hematological Oncology. 2019;37(S1):95-100. Published 12 June 2019. doi.org/10.1002/hon.2591

[49] Jin Z, Xiang R, Qing K, Kai Qing et al. The severe cytokine release syndrome in phase I trials of CD19-CAR-T cell therapy: a systemic review. Ann Hematol. 2018;97:1327-1335. PMID: 29766234 DOI: $10.1007 / \mathrm{s} 00277-018-3368-8$

[50] Jorge Garcia Borrega, Philipp Gödel, Maria Adele Rüger et al. In the Eye of the Storm: Immunemediated Toxicities Associated With CAR-T Cell Therapy. Hemasphere. 2019 Apr; 3(2): e191. doi: 10.1097/HS9.0000000000000191.

[51] Frederick L Locke Sattva S Neelapu , Nancy L Bartlett et al. Phase 1 Results of ZUMA-1: A Multicenter Study of KTE-C19 Anti-CD19 CAR T Cell Therapy in Refractory Aggressive Lymphoma. Mol Ther. 2017 Jan 4;25(1):285-295. doi: 10.1016/j.ymthe.2016.10.020.

[52] Stephen J. Schuster, M.D., Michael R. Bishop et al. Tisagenlecleucel in Adult Relapsed or Refractory Diffuse Large B-Cell Lymphoma. N Engl J Med 2019;380:45-56. DOI: 10.1056/NEJMoa1804980 [53] M. Wang, J. Munoz, A. Goy, F.L. Locke et al. KTE-X19 CAR T-Cell Therapy in Relapsed or Refractory Mantle-Cell Lymphoma. N Engl J Med 2020;382:1331-42. DOI: 10.1056/NEJMoa1914347

[54] Lars Frisén. Swelling of the optic nerve head: a staging scheme. J Neurol Neurosurg Psychiatry. 1982 Jan; 45(1): 13-18. doi: 10.1136/jnnp.45.1.13

[55] Fry TJ, Shah NN, Orentas RJ et al. CD22-targeted CAR T cells induce remission in B-ALL that is naive or resistant to CD19-targeted CAR immunotherapy. Nat Med; 2017. https://doi.org/10.1038/nm.4441. [56] Gattinoni L, Finkelstein SE, Klebanoff CA et al. Removal of homeostatic cytokine sinks by lymphodepletion enhances the efficacy of adoptively transferred tumor-specific CD8+ T cells. J Exp Med 2005; 202:907-12. doi: 10.1084/jem.20050732

[57] Klebanoff CA, Khong HT, Antony PA et al. Sinks, suppressors and antigen presenters: how lymphodepletion enhances T cell-mediated tumor immunotherapy. Trends Immunol 2005;26:111-7.

DOI: 10.1016/j.it.2004.12.003

[58] Kochenderfer JN, Yu Z, Frasheri D et al. Adoptive transfer of syngeneic T cells transduced with a chimeric antigen receptor that recognizes murine CD19 can eradicate lymphoma and normal B cells. Blood 2010;116:3875-86.

[59] Brudno JN and Kochenderfer JN. Recent advances in CAR T-cell toxicity: Mechanisms, manifestations and management Blood Rev. 2019 March ; 34: 45-55. doi:10.1016/j.blre.2018.11.002.

[60] Turtle CJ, Hay KA, Hanafi LA et al. Durable molecular remissions in chronic lymphocytic leukemia treated with CD19-specific Chimeric antigen receptor-modified T cells after failure of Ibrutinib. J Clin Oncol. 2017;35:3010-20. doi: 10.1200/JCO.2017.72.8519.

[61] Turtle CJ, Hanafi LA, Berger C et al. CD19 CAR-T cells of defined CD4+:CD8+ composition in adult B cell ALL patients. J Clin Invest. 2016;126:2123-38. doi: 10.1172/JCI85309

[62] Wang Y, Zhang WY, Han QW et al. Effective response and delayed toxicities of refractory advanced diffuse large B-cell lymphoma treated by CD20-directed chimeric antigen receptor-modified T cells. Clin Immunol. 2014;155:160-75. DOI: 10.1016/j.clim.2014.10.002

[63] Rouce RH, Heslop HE. Forecasting cytokine storms with new predictive biomarkers. Cancer Discov. 2016;6:579-80. DOI: 10.1158/2159-8290

[64] Park JH, Santomasso B, Riviere I et al. Baseline and early post-treatment clinical and laboratory factors associated with severe neurotoxicity following 19-28z CAR T cells in adult patients with relapsed B-ALL. J Clin Oncol. 2017;35:7024. DOI:10.1200/JCO.2017.35.15_SUPPL.7024

[65] Turtle CJ, Hay KA, Gust J et al. Cytokine release syndrome (CRS) and neurotoxicity (NT) after CD19specific chimeric antigen receptor- (CAR-) modified T cells. J Clin Oncol. 2017;35:3020. DOI:

10.1200/JCO.2017.35.15_suppl.302

[66] Park JH, Riviere I, Wang XY et al. Impact of disease burden on long-term outcome of 19-28z CAR modified T cells in adult patients with relapsed B-ALL. J Clin Oncol. 2016;34:7003.

DOI: 10.1200/JCO.2016.34.15_suppl.7003 
[67] Porter D, Frey N, Wood PA, et al. Grading of cytokine release syndrome associated with the CAR T cell therapy tisagenlecleucel [published correction appears in J Hematol Oncol. 2018;11:81]. J Hematol Oncol. 2018;11:35. Medline, Google Scholar. doi: 10.1186/s13045-018-0571-y.

[68] Jennifer N Brudno and James N Kochenderfer. Recent advances in CAR T-cell toxicity: Mechanisms, manifestations and management. Blood Rev. 2019 Mar;34:45-55. doi: 10.1016/j.blre.2018.11.002.

[69] EMEA. Summary of Product Characteristics, Yescarta. s.1. : http://www.ema.europa.eu.

[70] La Rosee, Paul, Paul La Rosée, AnnaCarin Horne, Melissa Hines et al. Recommendations for the management of hemophagocytic lymphohistiocytosis in adult. Blood (2019) 133 (23): 2465-2477. https://doi.org/10.1182/blood.2018894618

[71] Kitsada Wudhikarn, Martina Pennisi, Marta Garcia-Recio et al. DLBCL patients treated with CD19 CAR T cells experience a high burden of organ toxicities but low nonrelapse mortality. Blood Adv (2020) 4 (13): 3024 - 3033. https://doi.org/10.1182/bloodadvances.2020001972

[72] Ying Wang, Kunming Qi, Hai Cheng et al. Coagulation Disorders after Chimeric Antigen Receptor T Cell Therapy: Analysis of 100 Patients with Relapsed and Refractory Hematologic Malignancies. Biol Blood Marrow Transplant . 2020 May;26(5):865-875. doi: 10.1016/j.bbmt.2019.11.027.

[73] Kitsada Wudhikarn, M. Lia Palomba, Martina Pennisi et al. Infection during the first year in patients treated with CD19 CAR T cells for diffuse large B cell lymphoma. Blood Cancer Journal volume 10, Article number: 79 (2020)

[74] Mestermann K, Giavridis T, Weber J, et al. The tyrosine kinase inhibitor dasatinib acts as a pharmacologic on/off switch for CAR T cells. Sci Transl Med. 2019 Jul 3;11(499):eaau5907. doi: 10.1126/scitranslmed.aau5907.

[75] Cesar Clavijo Simbaqueba, Maria Patarroyo Aponte, Peter Kim et al. Cardiovascular Complications of Chimeric Antigen Receptor T-Cell Therapy: The Cytokine Release Syndrome and Associated Arrhythmias. J Immunother Precis Oncol. 2020; 3:113-120. DOI: 10.36401/JIPO-20-10.

[76] Hamza Hashmi, Abu-Sayeef Mirza, Alicia Darwin et al. Venous thromboembolism associated with CD19-directed CAR T-cell therapy in large B-cell lymphoma. Blood Adv (2020) 4 (17): 4086-4090. doi.org/10.1182/bloodadvances.2020002060

[77] J. S Abramson, M Lia Palomba, Leo I Gordon, M. A Lunning, M.1 Wang, Jon Arnason et al. Lisocabtagene maraleucel for patients with relapsed or refractory large B-cell lymphomas (TRANSCEND NHL 001): a multicentre seamless design study.

Lancet 2020; 396: 839-52. https://doi.org/10.1016/ S0140-6736(20)31366-0

[78] BREYANZI ${ }^{\circledR}$ (lisocabtagene maraleucel) FDA, full prescribing information

https://www.fda.gov/media/145711/download 